\title{
Scapholunate Ligament Internal Brace 360 Tenodesis (SLITT) Procedure: A Biomechanical Study
}

\author{
Sanjeev Kakar, MD, FAOA ${ }^{1} \quad$ Ryan M. Greene, DO, MS ${ }^{1} \quad$ Janet Denbeigh, $\mathrm{PhD}^{1} \quad$ Andre Van Wijnen, $\mathrm{PhD}^{1}$ \\ ${ }^{1}$ Department of Orthopedic Surgery, Mayo Clinic, Rochester, Minnesota \\ Address for correspondence Sanjeev Kakar, MD, FAOA, Department \\ J Wrist Surg 2019;8:250-254. \\ of Orthopedic Surgery, Mayo Clinic, 200 First Street SW, Rochester, \\ MN 55902 (e-mail: Kakar.Sanjeev@mayo.edu).
}

\begin{abstract}
\section{Keywords}

- internal brace

- scapholunate instability

- scapholunate reconstruction

- suture tape

- internal brace augmentation
\end{abstract}

Background Twelve paired fresh frozen cadaveric wrists were randomized to a 360degree tenodesis repair group or the 360-degree tenodesis repair with an internal brace (suture tape) construct.

Case Description The specimens were preloaded to $5 \mathrm{~N}$ and subsequently biomechanically loaded to failure, at a rate of $0.1 \mathrm{~mm} / \mathrm{s}$ on a jig that allowed for axial load. The maximum load and mode of failure were recorded. Load to failure in the 360 tenodesis group with internal brace was $283.47 \pm 100.25 \mathrm{~N}$, compared with the 360 tenodesis group only, whose yield strength was $143.61 \pm 90.54 \mathrm{~N}$. The mode of failure within the internal brace construct was either through knot slippage, graft disruption, or bone separation from strength testing construct. The 360 tenodesis group tended to fail via graft slippage or graft rupture.

Literature Review The management of scapholunate instability can be a difficult problem to treat. Traditionally, many of the surgical reconstructions have focused upon dorsal ligament reconstruction with Kirschner $(K)$ wire fixation. This results in prolonged immobilization of the wrist with varied outcomes, in part due to the multiaxial instability that may persist due to concomitant volar ligament disruption. To address this instability, surgical techniques have been devised that address both the volar and dorsal ligament injuries.

Clinical Relevance Scapholunate reconstruction with a 360-degree tenodesis and internal brace augmentation (SLITT procedure) provided superior biomechanical stability than tenodesis alone.
Scapholunate (SL) joint instability is one of the most common injuries of the wrist joint and may result from a fall or high energy mechanism on the outstretched hand. If unrecognized, the injury may lead to functional impairment and posttraumatic arthritis. $^{1-3}$

Since its initial description, ${ }^{4}$ a myriad of different surgical techniques have been devised with varied success. These include capsular shrinkage, dorsal capsulodesis, reductionassociation with a screw of the scapholunate joint (RASL), scapholunate axis method (SLAM), bone ligament bone grafts, and a variety of tendon reconstruction. ${ }^{5-12}$ Many of these constructs require prolonged immobilization with Kirschner (K) wire stabilization, which may break, become infected, or

received

March 20, 2018

accepted

August 2, 2018

published online

September 18, 2018

require a secondary procedure for their removal. In addition, the outcomes of scapholunate reconstructions can be unpredictable. Possible explanations for this varied outcome may be related to the use of soft tissue reconstructions for irreducible injuries and reconstruction of only the dorsal SL ligament. Indeed, the sectioning studies by Berger ${ }^{13}$ noted that, while the dorsal SL ligament has a yield strength of close to $300 \mathrm{~N}$, the palmar region provides $120 \mathrm{~N}$ of breaking strength. To try and correct the torsional instability that may result from dorsal only repairs, recent techniques have been described that address both dorsal and volar SL ligaments. ${ }^{14,15}$

The purpose of this study was to compare the biomechanical strength of a 360-degree tenodesis to one augmented

Copyright ( $) 2019$ by Thieme Medical Publishers, Inc., 333 Seventh Avenue, New York, NY 10001, USA. Tel: +1(212) 584-4662.
DOI https://doi.org/ $10.1055 / \mathrm{s}-0038-1670682$. ISSN 2163-3916. 
with an internal brace (suture tape) in a cadaveric model and determine whether the stability achieved reaches normative yield strength of native SL ligament.

\section{Materials and Methods}

We obtained 12 paired fresh frozen cadaveric wrists, average age 50.5 years (range: $41-65$ ) for testing (- Table 1). Preprocedural imaging demonstrated no evidence of carpal malalignment, preexisting wrist arthritis, or previous surgery. To test the yield strength of the reconstructions, and to remove any confounding variables provided by secondary stabilizers of the carpus, ${ }^{16-18}$ each of the 24 specimens was disarticulated from the radiocarpal joint, the SL ligament sectioned and randomized to 360-degree tenodesis reconstruction group or the 360-degree tenodesis with an internal brace. All procedures were performed by the senior surgeon. A 0.035 inch K wire was placed from dorsal to volar through the center of the lunate and proximal scaphoid and confirmed on fluoroscopic imaging. Once the desired central trajectory had been confirmed, a $2.5 \mathrm{~mm}$ cannulated drill hole was made within the scaphoid and a $3.0 \mathrm{~mm}$ hole made within the lunate. A $15 \mathrm{~cm}$ palmaris longus graft was procured and whip stitched at either end using a 4-0 fiberloop suture. Using a tendon passer, the tendon graft was passed from dorsal to volar through the lunate, volar to dorsal through the scaphoid, and dorsal to volar through the lunate (-Fig. 1). In this way, a 360-degree tenodesis had been performed. Maximum tension was placed by the surgeon pulling onto the tails of the graft to aid in reduction of the SL and the wrist ranged in flexion to extension to remove any creep from the construct. Two $3 \times 8 \mathrm{~mm}$ biotenodesis screws were then placed within the scaphoid and lunate to secure the graft and the tendon tails cut flush (-Fig. 2). Within the internal brace cohort, a similar procedure was performed. A $1.3 \mathrm{~mm}$ suture tape was then passed from dorsal to volar through the cannulation of the biotenodesis screws within the scaphoid and lunate and tied palmarly. The purpose of central passage through the screw holes was to prevent the suture tape from cutting through the cortical bone, if placed directly through the bone tunnels (-Figs. 3 and $\mathbf{4}$ ).

To prepare for biomechanical testing, the scaphoid, lunate, and triquetrum were removed en bloc and a vertically orientated $\mathrm{K}$ wire was placed through the scaphoid and lunate, with care taken to avoid the scapholunate ligament reconstruction. Specimens were then potted in 1.5 inch polyvinyl chloride (PVC) piping and mounted into an Instron machine and preloaded to $5 \mathrm{~N}$. An axial distraction load was then applied at a rate of $0.1 \mathrm{~mm} / \mathrm{s}$ until failure of the reconstruction. The mode of and maximum load to failure were recorded for each sample.

One way analysis of variance with a Tukey significant difference post hoc analysis was performed with $p<0.05$ for stiffness by group and maximum breaking strength (maximum load) by group, for all specimens.

Table 1360 tenodesis reconstruction/360 tenodesis with suture tape internal brace fixation

\begin{tabular}{|c|c|c|c|c|c|c|}
\hline \multirow[b]{2}{*}{ Sample } & \multicolumn{3}{|c|}{360 tenodesis reconstruction } & \multicolumn{3}{|c|}{360 tenodesis with suture tape internal brace } \\
\hline & $\begin{array}{l}\text { Stiffness } \\
(\mathrm{N} / \mathrm{mm})\end{array}$ & $\begin{array}{l}\text { Maximum } \\
\text { load }(\mathrm{N})\end{array}$ & Mode of failure & $\begin{array}{l}\text { Stiffness } \\
(\mathrm{N} / \mathrm{mm})\end{array}$ & $\begin{array}{l}\text { Maximum } \\
\text { load }(\mathrm{N})\end{array}$ & Mode of failure \\
\hline 1 & 46.57 & 159.28 & $\begin{array}{l}\text { Graft tore through } \\
\text { bone tunnel }\end{array}$ & 42.16 & 300.05 & Suture knot failure \\
\hline 2 & 24.75 & 132.91 & Anchor failure of graft & 56.9 & 98.10 & Suture knot failure \\
\hline 3 & 36.07 & 113.72 & Anchor failure of graft & 31.1 & 218.97 & Anchor failure of graft \\
\hline 4 & 24.34 & 87.51 & Graft slippage & 67.14 & 252.83 & Anchor failure of graft \\
\hline 5 & 51.07 & 266.07 & $\begin{array}{l}\text { Graft slippage with some } \\
\text { tearing into bone tunnel }\end{array}$ & 38.94 & 334.65 & Anchor failure of graft \\
\hline 6 & 77.87 & 366.38 & $\begin{array}{l}\text { Graft slippage with some } \\
\text { tearing into bone tunnel }\end{array}$ & 57.28 & 339.86 & Suture knot failure \\
\hline 7 & 20.40 & 61.06 & $\begin{array}{l}\text { Graft slippage with some } \\
\text { tearing into bone tunnel }\end{array}$ & 29.30 & 409.13 & Graft and suture tape failure \\
\hline 8 & 17.70 & 104.37 & $\begin{array}{l}\text { Graft tore through } \\
\text { bone tunnel }\end{array}$ & 46.9 & 186.81 & Bone tunnel failure \\
\hline 9 & 17.80 & 112.52 & Graft slippage & 36.4 & 347.16 & Failure of biotenodesis screw \\
\hline 10 & 24.50 & 84.57 & Graft slippage & 24.3 & 322.05 & $\begin{array}{l}\text { Graft slippage with some } \\
\text { tearing into bone tunnel }\end{array}$ \\
\hline 11 & 33.30 & 176.54 & Graft slippage & 42.4 & 426.44 & $\begin{array}{l}\text { Graft slippage with some } \\
\text { tearing into bone tunnel }\end{array}$ \\
\hline 12 & 9.93 & 58.39 & Graft slippage & 30.3 & 165.57 & $\begin{array}{l}\text { Graft slippage with some } \\
\text { tearing into bone tunnel }\end{array}$ \\
\hline Mean & 32.03 & 143.61 & & 41.3 & 283.47 & \\
\hline SD & 18.81 & 90.54 & & 13.08 & 100.25 & \\
\hline
\end{tabular}

Abbreviation: SD, standard deviation. 


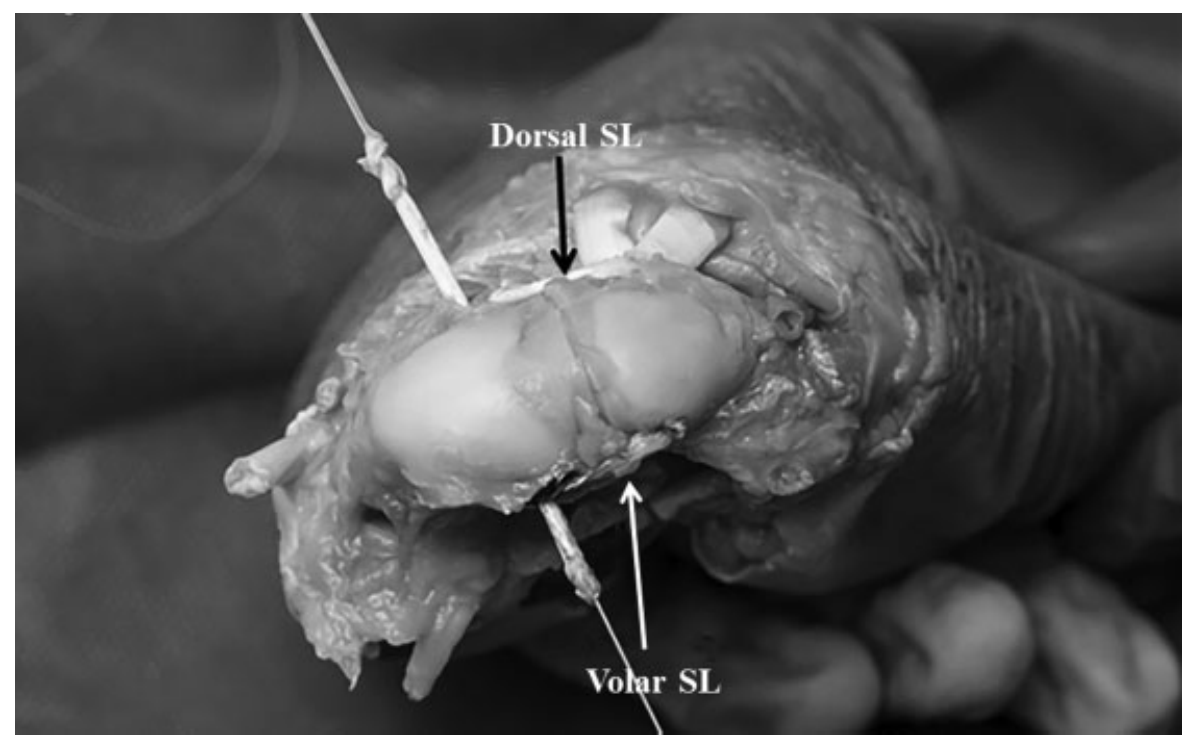

Fig. 1 Cadaveric specimen showing reconstruction of the dorsal and volar scapholunate (SL) ligament.

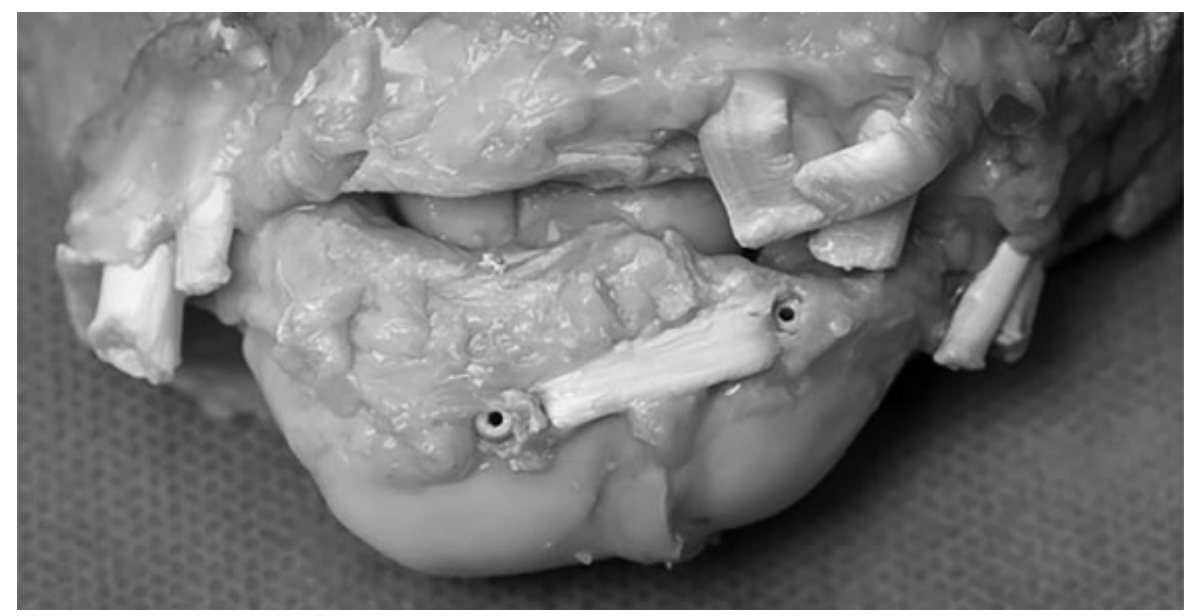

Fig. 2 Dorsal scapholunate ligament reconstruction with biotenodesis screw fixation.

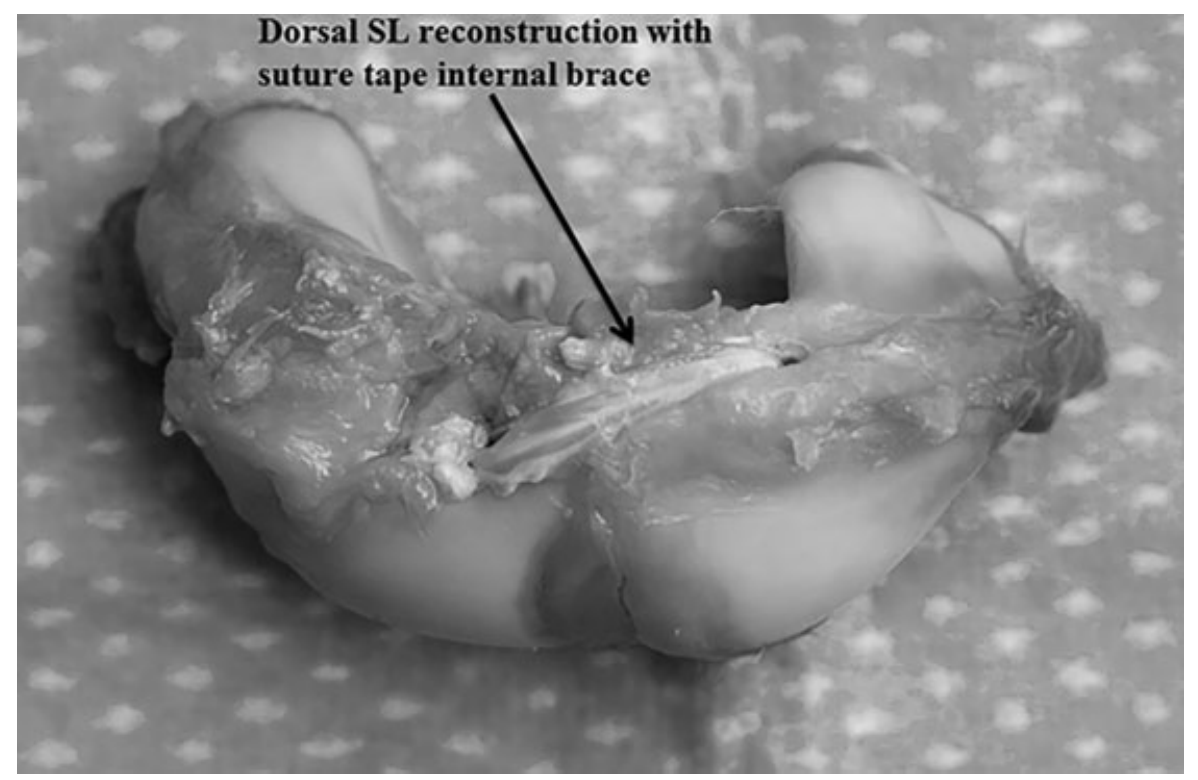

Fig. 3 Dorsal aspect of scapholunate (SL) reconstruction with internal brace with the proximal carpal row disarticulated prior to biomechanical testing. 


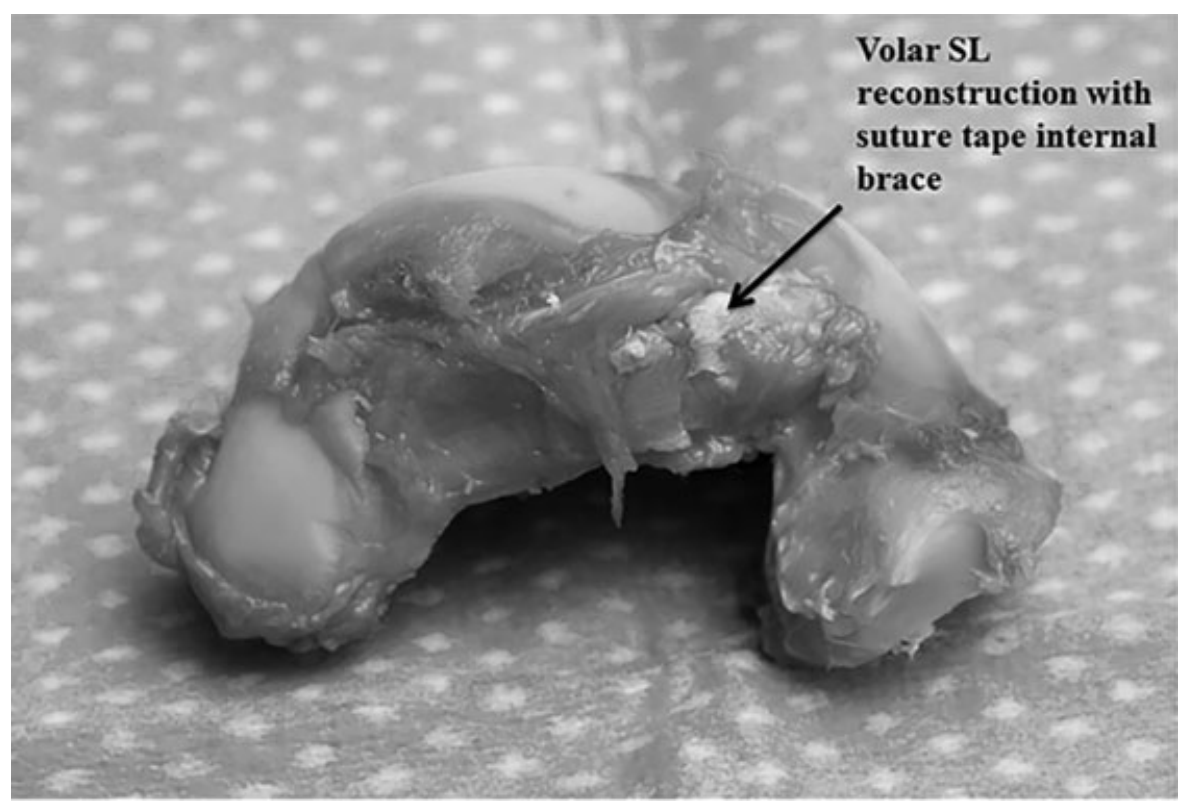

Fig. 4 Volar aspect of scapholunate (SL) reconstruction with internal brace with the proximal carpal row disarticulated prior to biomechanical testing.

\section{Results}

Specimens that underwent loading after 360-degree tenodesis only demonstrated a breaking strength of $143.61 \pm 90.54 \mathrm{~N}$. A total of 8 samples of 12 failed via tendon graft slippage at the bone screw interface (-Table 1). Constructs that were augmented with an internal brace (suture tape) had a breaking strength of $283.47 \pm 100.25 \mathrm{~N}$ ( $\mathrm{p} \leq 0.002$; - Table 1). Common modes of failure included graft slippage or knot breakage of the suture tape $(-$ Table 1$)$.

\section{Discussion}

The treatment of scapholunate instability continues to vex surgeons. The injury pattern ranges from a minor sprain to gross disruption of the ligament with altered carpal kinematics. Many techniques have been proposed and are based upon controlling the scaphoid that assumes a position of flexion and pronation. ${ }^{1,6-8,10,13-15,17,19-23}$ Berger's detailed anatomic prosections noted that the SL ligament comprised of a dorsal, membranous, and volar region. The palmar ligament had a yield strength of $120 \mathrm{~N}$ compared with that of the dorsal ligament, which exhibited a breaking strength of $300 \mathrm{~N}$. Given this, traditional techniques had concentrated on reconstructing the dorsal ligament only. Garcia-Elias et al $^{1}$ reported on the outcomes of the triligament tenodesis technique in 38 patients at an average follow-up of 46 months. Twenty-eight patients reported no pain and 29 returned to their original occupation. Of note, $18 \%$ of patients developed mild signs of arthritis. Patients were immobilized for a prolonged period of time and required a secondary procedure for $\mathrm{K}$ wire removal at an average of 8 weeks, postoperatively.

As load is transferred across the SL joint, the morphology of the SL ligament remains important to resist torsional and translational moments. Indeed, one of the reasons why there may be unpredictable outcomes in traditional dorsal ligament reconstruction techniques is the failure to repair the volar ligament. Albeit not as strong as the dorsal segment, it may aid in resisting rotation across the joint. ${ }^{13}$ As such, there has been an increasing interest to address the volar SL ranging from volar capsulodesis ${ }^{23}$ to circumferential grafts around the scaphoid and lunate. ${ }^{24}$ As reported by Chee et al, ${ }^{14}$ a strip of the flexor carpi radialis (FCR) tendon can be passed from volar to dorsal through the scaphoid and dorsal to volar through the triquetrum in an antipronation tenodesis to correct carpal malalignment. Ho et $\mathrm{al}^{24}$ described an arthroscopic-assisted technique of reconstructing the volar and dorsal SL ligament using a palmaris longus graft. Seventeen patients with chronic SL instability were treated and followed-up on average for 48 months. Eleven of 17 patients reported no pain, the average SL gap was $2.9 \mathrm{~mm}$ and 13 patients returned to their preinjury job level. There was one case of scaphoid ischemia that did not progress or become symptomatic. Similar results have been reported by Henry following volar and dorsal SLIL repair with immobilization for 10 to 12 weeks. ${ }^{15}$ Pin removal occurred at 8 weeks, postoperatively.

Many of the treatments for SL instability involve prolonged casting and $\mathrm{K}$ wire augmentation. Mathoulin et $\mathrm{al}^{25}$ described results of arthroscopic dorsal capsuloligamentous repair with mean follow-up of 11.4 months in 36 patients. Patients were immobilized via cast fixation for 8 weeks, when $\mathrm{K}$ wires were removed (16 cases) and physical therapy protocol was initiated. Patient grip strength on average increased to $92 \%$ of unaffected side with significant reduction in VAS (visual analogue scale) score (mean VAS score $=0.5 / 10$ ).

The concept of the 360-degree tenodesis is to provide resistance to load along multiple axial planes. Compared with tenodesis only the addition of suture tape internal bracing resulted in construct yield strengths similar to the native dorsal SL ligament. ${ }^{13,20,26}$ Given this inherent immediate 
stability, we feel it may permit earlier range of motion in patients without the need for prolonged immobilization, under the care of a certified hand therapist to monitor function. In addition, given its inherent strength, K wires may not be needed as the suture tape may prevent the creep of the tendon graft, when load is initially applied to it. Taleisnik described two forms of SL instability: type 1, in which the ulnar is anatomically located within the ulnar facet of the distal radius; and type 2, whereby there is ulnar translocation of the lunate. ${ }^{11}$ An additional advantage of this procedure is the ability of the palmar tail of the tendon graft and suture tape to be secured to the volar rim of the distal radius to reconstruct the long radiolunate ligament and provide a restraint to carpal translocation.

As with most biomechanical studies, there are inherent limitations to replicating the natural forces that would be present in vivo. The model tested the breaking strength of the fixation methods and did not factor in the strength of the soft tissues after their healing response. It is unknown whether the tendon grafts would have stretched out over time for which the internal brace provides immediate stability. There is variability in the cadavers including their bone quality. To mitigate this, we used 12 matched pairs of cadavers. Lastly, the number of specimens tested may have accounted for a type 2 error in the tenodesis and internal brace construct. Notwithstanding these limitations, the 360-degree tenodesis with suture tape internal brace provides immediate stability of the SL joint akin to native SL ligament strengths, permits earlier range of motion with encouraging early clinical results, and can provide a checkrein to ulnar translocation of the carpus.

The proposed 360-degree tenodesis technique presented in this paper aims to permitting immediate construct stability that replicates native SLyield strength. The augmentation with the suture tape internal brace may be better suited to resist immediate loads and diastasis of the SL joint, while at the same time possibly obviating the need for K wire stabilization.

\section{Ethical Approval}

This study was performed at Arthrex HQ in Naples, Florida and was conducted per their review board.

\section{Conflict of Interest}

Sanjeev Kakar is a Consultant for Arthrex but did not receive any personal renumeration for this study.

\section{Acknowledgment}

The authors would like to thank Arthrex Inc. for provision of cadavers and instrumentation used for testing.

\section{References}

1 Garcia-Elias M, Lluch AL, Stanley JK. Three-ligament tenodesis for the treatment of scapholunate dissociation: indications and surgical technique. J Hand Surg Am 2006;31(01):125-134

2 Pomerance J. Outcome after repair of the scapholunate interosseous ligament and dorsal capsulodesis for dynamic scapholunate instability due to trauma. J Hand Surg Am 2006;31(08):1380-1386
3 Rainbow MJ, Wolff AL, Crisco JJ, Wolfe SW. Functional kinematics of the wrist. J Hand Surg Eur Vol 2016;41(01):7-21

4 Linscheid RL, Dobyns JH, Beabout JW, Bryan RS. Traumatic instability of the wrist. Diagnosis, classification, and pathomechanics. J Bone Joint Surg Am 1972;54(08):1612-1632

5 Blatt G. Capsulodesis in reconstructive hand surgery. Dorsal capsulodesis for the unstable scaphoid and volar capsulodesis following excision of the distal ulna. Hand Clin 1987;3(01):81-102

6 Brunelli GA, Brunelli GR. A new technique to correct carpal instability with scaphoid rotary subluxation: a preliminary report. J Hand Surg Am 1995;20(3, Pt 2):S82-S85

7 Darlis NA, Kaufmann RA, Giannoulis F, Sotereanos DG. Arthroscopic debridement and closed pinning for chronic dynamic scapholunate instability. J Hand Surg Am 2006;31(03):418-424

8 Darlis NA, Weiser RW, Sotereanos DG. Partial scapholunate ligament injuries treated with arthroscopic debridement and thermal shrinkage. J Hand Surg Am 2005;30(05):908-914

9 Linscheid RL, Dobyns JH. Treatment of scapholunate dissociation. Rotatory subluxation of the scaphoid. Hand Clin 1992;8(04): 645-652

10 Moran SL, Cooney WP, Berger RA, Strickland J. Capsulodesis for the treatment of chronic scapholunate instability. J Hand Surg Am 2005;30(01):16-23

11 Taleisnik J. The Wrist. Churchill Livingstone, NY; 1985

12 Van Den Abbeele KL, Loh YC, Stanley JK, Trail IA. Early results of a modified Brunelli procedure for scapholunate instability. J Hand Surg [Br] 1998;23(02):258-261

13 Berger RA. The gross and histologic anatomy of the scapholunate interosseous ligament. J Hand Surg Am 1996;21(02):170-178

14 Chee KG, Chin AY, Chew EM, Garcia-Elias M. Antipronation spiral tenodesis-a surgical technique for the treatment of perilunate instability. J Hand Surg Am 2012;37(12):2611-2618

15 Henry M. Reconstruction of both volar and dorsal limbs of the scapholunate interosseous ligament. J Hand Surg Am 2013;38 (08):1625-1634

16 Short WH, Werner FW, Green JK, Masaoka S. Biomechanical evaluation of ligamentous stabilizers of the scaphoid and lunate. J Hand Surg Am 2002;27(06):991-1002

17 Short WH, Werner FW, Green JK, Masaoka S. Biomechanical evaluation of the ligamentous stabilizers of the scaphoid and lunate: Part II. J Hand Surg Am 2005;30(01):24-34

18 Short WH, Werner FW, Green JK, Sutton LG, Brutus JP. Biomechanical evaluation of the ligamentous stabilizers of the scaphoid and lunate: part III. J Hand Surg Am 2007;32(03):297-309

19 Aviles AJ, Lee SK, Hausman MR. Arthroscopic reduction-association of the scapholunate. Arthroscopy 2007;23(01):105.e1-105.e5

20 Berger RA, Imeada T, Berglund L, An KN. Constraint and material properties of the subregions of the scapholunate interosseous ligament. J Hand Surg Am 1999;24(05):953-962

21 Kitay A, Wolfe SW. Scapholunate instability: current concepts in diagnosis and management.J Hand Surg Am 2012;37(10):2175-2196

22 Yao J, Zlotolow DA, Lee SK. ScaphoLunate Axis Method. J Wrist Surg 2016;5(01):59-66

23 van Kampen RJ, Bayne CO, Moran SL. A new technique for volar capsulodesis for isolated palmar scapholunate interosseous ligament injuries: a cadaveric study and case report. J Wrist Surg 2015;4(04):239-245

24 Ho PC, Wong CW, Tse WL. Arthroscopic-assisted combined dorsal and volar scapholunate ligament reconstruction with tendon graft for chronic SL instability. J Wrist Surg 2015;4(04):252-263

25 Mathoulin CL, Dauphin N, Wahegaonkar AL. Arthroscopic dorsal capsuloligamentous repair in chronic scapholunate ligament tears. Hand Clin 2011;27(04):563-572

26 Berger RA, Blair WF, Crowninshield RD, Flatt AE. The scapholunate ligament. J Hand Surg Am 1982;7(01):87-91 